\title{
The Effects of P-O Fit and P-J Fit on Turnover Intention
}

\author{
Qingsong Zhu, Tingting Li * \\ School of Business, Sichuan University, China \\ *Corresponding author
}

Keywords: P-O fit, P-J fit, Career Growth, Turnover Intention.

\begin{abstract}
In this paper, we construct a model of the relationship between P-O fit, P-J fit and turnover intention based on the theory of Person-Environment matching, then introduce career growth as mediating variable to discuss the effect of the matching degree on turnover intention. Through the regression analysis of the 183 employee samples obtained, P-O fit and P-J fit both have significant negative predictive effect on turnover intention, and the prediction power of P-J fit was slightly larger than P-O fit. Besides, career growth has a partial mediating effect between P-O fit, P-J fit and turnover intention.
\end{abstract}

\section{Introduction}

Employee turnover has always been a major problem for the management of enterprises, because it will bring the loss of human capital investment and the cost of replacement). With the arrival of boundaryless career, employees' frequent job hopping has become a serious problem that enterprises must pay attention to, so the factors and mechanism of labor turnover become an important research topic in human resource management[1].

At present, there are lots of studies on Turnover intention antecedents, and scholars mainly focus on the individual and environment level and give less attention to the influence of the fitting of people and environment on employee' turnover intention. In the multidimensional structure of the fitting, P-O fit and P-J fit have been widely concerned and studied by scholars because of their best explanatory power. But in a small amount of compatibility and the relationship between the turnover intention of study, most of scholars focus on the influence of P-O fit(Merije et al, 2013), to study the influence of P-J fit is less, and combine the P-O and P-J fit to discuss research is lack. Therefore, this article meaning respectively discuss and explanatory the predictive power of P-O fit and P-J fit on turnover intention, fill the blank of the relevant theory.

Employees' career growth, on the other hand, became a hot topic in the early 1980s, and has been widely attention of academia and enterprise managers(Malos, 1995; Nabi, 2000). This paper tries to introduce career growth as a intervening variable, explore whether P-O fit, P-J fit can through acting on employee career growth impact on turnover intention, with clear compatibility mechanism of turnover intention, provide a reference for future theoretical research and management practice.

\section{Theory Review and Research Hypotheses}

\subsection{P-O Fit, P-J Fit and Turnover Intention.}

P-J fit refers to the competency of employees and the requirements of the job match (Adkins, 1994), or the needs and aspirations that employees can be satisfied from the job[2] . P-O fit refers to the value of employees and corporate culture or ideas to match, including consistency matching and complementary matching[3].

Schneider (1987) proposed an attractive-choice-friction (ASA) model, suggesting that employees would be more likely to be attracted to organizations that similar to their own personality characteristics, that is to say employees choose whether to stay in the original organization depends largely on its perceived with the enterprise for various aspects the matching degree (Judge, 1997). On 
the other hand, Kristof based on "ASA" focuses on the analysis of the P-J fit about job needs and personal ability, he thought, P-J fit is pay more attention to whether employees have the ability to perform job tasks, rather than the relationship between the employees and organization, that is to say, P-J fit emphasis on employees' working ability. Above all, we tested the following hypothesis:

Hypothesis 1: (a)P-O fit and (b)P-J fit will be negatively related to turnover intention.

\subsection{P-O Fit, P-J Fit and Career Growth.}

Career growth within organization refers to the employee's career progress speed within the organization, including four dimensions: professional ability development, career goal progress, promotion speed and remuneration growth. The development of professional ability refers to the promotion of the current work to the professional skills, knowledge and work experience of the staff; The development of career goals refers to the relationship between current job and career goals, career development; Promotion speed refers to the speed of promotion and promotion space in the current work units; Compensation growth mainly refers to the salary increase speed and the possibility of continue to improve for the staff in the current organization"[4].

The theory of "similar-attract" points out that when the P-O fit is good, individuals in the work show a positive attitude and behavior. Organ (1977) suggested that when the value of the employee and the organization is highly matched, the employee will put more effort into the work and show more organizational citizenship behavior. In addition, the theory of mutual choice of human industry points out that when the P-J matching degree is high, the individual can give full play to their own advantages in their position and obtain good performance ii. Zhao \&Long (2010) pointed out that from the perspective of individual development motivation, the individual was more willing to stay with their knowledge, skills and ability to match the position of the organization. Above, we tested the following hypothesis:

Hypothesis 2: (a)P-O fit and (b)P-J fit will be positively related to career growth.

\subsection{The Intervening Role of Career Growth.}

In the boundaryless career era, profession and work flow is becoming a common phenomenon, whether can get professional growth gradually become one of the major problems people are considering to stay or leave, and career growth can negatively predicted turnover intention[5] . Therefore, it is necessary to explore the influence of fit degree on turnover intention from the perspective of career growth.

The rapid career growth can inhibit the generation of turnover intention. Colarelli \& Bishop (1990) found that the career growth opportunities significantly negatively correlated with turnover intention. Weng(2010) through further analysis obtained, the staff who got faster growing will have a positive effect on enterprises and turnover intention was low. Yuan (2014) confirmed that the career development of knowledge workers was negatively correlated with turnover intention, and both organizational identification and professional identity played a moderating role. Above all, the following hypothesis was tested:

Hypothesis 3: Career growth will mediate the relationship between (a)P-O fit, (b) P-J fit and turnover intention.

\section{Study Design}

\subsection{Sample.}

The research object is enterprise employee. We combined online and offline ways to collect questionnaire, including emails, throughing social networking platform and papering to all kinds of enterprises. Finally, we received a total of 224 questionnaires and hold 183 valid questionnaires. Table 1 is the descriptive statistics of the sample. 
Table 1 Sample Analysis

\begin{tabular}{|c|c|c|c|c|c|c|c|c|c|c|c|}
\hline \multicolumn{2}{|c|}{ Gender } & \multicolumn{2}{|c|}{ Age } & \multicolumn{2}{|c|}{ Education level } & \multicolumn{2}{|c|}{ Working life } & \multicolumn{2}{|c|}{ Position level } & \multicolumn{2}{|c|}{ Company type } \\
\hline \multirow{3}{*}{ male } & \multirow{3}{*}{$43 \%$} & & & & & $<=1$ & & & 80 & & 15 \\
\hline & & $<=25$ & $48 \%$ & special & $2 \%$ & years & $40 \%$ & General & $\%$ & SUE & $\%$ \\
\hline & & 26-35 & $27 \%$ & $\begin{array}{c}\text { Associat } \\
\mathrm{e}\end{array}$ & $22 \%$ & $1-3$ & $22 \%$ & first-line & $\begin{array}{l}13 \\
\%\end{array}$ & private & $\begin{array}{l}43 \\
\%\end{array}$ \\
\hline \multirow{2}{*}{ female } & \multirow{2}{*}{$57 \%$} & $36-45$ & $19 \%$ & Bachelor & $68 \%$ & $4-6$ & $7 \%$ & middle & $6 \%$ & $\begin{array}{c}\text { institutio } \\
\mathrm{n}\end{array}$ & $\begin{array}{l}35 \\
\%\end{array}$ \\
\hline & & $>=4$ & $6 \%$ & Master & $8 \%$ & $\begin{array}{l}>=7 \\
\text { years }\end{array}$ & $31 \%$ & top & $1 \%$ & others & $7 \%$ \\
\hline
\end{tabular}

\subsection{Measures.}

P-O fit, P-J fit were measured by M. Saks \& E. Ashforth's(1997)4-item scales. Career growth was tested by Weng \&Xi's (2011) 15- item scale. The scale to measure turnover intention is based on O. Reilly's (1986)4-item, and combined with other scholars' research results to modify , finally holding a total of 3-item. All of the items in the questionnaire employed a five-point Likert format(1=strongly disagree, $5=$ strongly agree) .

\section{Data Analysis}

In this study, we used SPSS19 and AMOS17. 0 to complete data analysis.

\subsection{Reliability and Validity Test.}

SPSS19 was used to test the reliability of each subscale and total scale, and the consistency coefficient of P-O fit, P-J fit, career growth and turnover intention was $0.836,0.828,0.924,0.826$. The overall alpha consistency coefficient is 0 . 892, meeting the internal consistency reliability requirements. We used AMOS17. 0 to conduct confirmatory factor analysis (CFA) of the questionnaire, the results showed that the whole model fitted well. ( $2 / \mathrm{DF}=2.958, \mathrm{NFI}=0.794$, $\mathrm{RFI}=0.754, \mathrm{IFI}=0.854, \mathrm{CFI}=0.851, \mathrm{RMSEA}=0.082$ ), indicating the structural validity of the questionnaire meets the basic requirements.

\subsection{Descriptive Statistics Analysis and Correlation Analysis.}

It can be seen from table 2 that there is a significant correlation between the variables. The correlation coefficient between $\mathrm{P}-\mathrm{O}$ fit and turnover intention was -. $674(\mathrm{P}<.01)$, and the correlation coefficient between P-J fit and turnover intention was -. $686(\mathrm{P}<.01)$, assuming that Hypothesis 1 was supported.

Table 2 Means, Standard Deviations and Correlations of Study Variable (N=183)

\begin{tabular}{lcccccc}
\hline & \multirow{2}{*}{$\mathbf{M}$} & SD & \multicolumn{5}{c}{ Correlations } \\
\cline { 5 - 7 } & & & $\mathbf{1}$ & $\mathbf{2}$ & $\mathbf{3}$ & $\mathbf{4}$ \\
\hline 1P-O fit & 3.29 & 0.82 & $.688^{* *}$ & 1 & & \\
2P-J fit & 3.10 & 0.76 & $.631^{* *}$ & $.535^{* *}$ & 1 & \\
3Career Growth & 3.28 & 1.03 & $-.674^{* *}$ & $-.686^{* *}$ & $-.591^{* *}$ & 1 \\
4Turnover Intention & & & & &
\end{tabular}

Notes **. $\mathrm{P}<.01 . * . \mathrm{P}<.05$.

\subsection{Independent Sample T-Test and ANOVA.}

The control variables of this study including gender, age, education level, working life, position level and company type. We used the independent sample T test and variance analysis(ANOVA)to analyze the influence of the control variables on the research variables. The results showed that only age and working life can make a difference on research variables, so we should control them in following analysis. 


\subsection{Regression Analysis.}

The mediating effect analysis was based on Three-step test which recommended by Wen el at. (2004)[6]. (Table 3)First of all, executing the regression analysis of the independent variable P-O fit, P-J fit and dependent variable turnover intention, and test whether the coefficient is significant(Model $\left.4, \beta_{\mathrm{p}-0}=-.824 ; \beta_{\mathrm{p}-\mathrm{j}}=-.914, \mathrm{P}<.05\right)$. Then, we examined the regression of independent variables to the career growth of intermediary variables and check whether the regression coefficient is significant, (Model 2, $\beta_{\mathrm{p}-\mathrm{o}}=.579 ; \beta_{\mathrm{p}-\mathrm{j}}=.533, \mathrm{P}<.05$ ). Finally, We did the regression analysis of independent variables and mediating variables on the dependent variables and examine whether the regression coefficient is significant, (Model 5, $\beta_{\mathrm{p}-\mathrm{o}}=-.608, \beta_{\mathrm{CG}}=-$. 374; $\beta_{\mathrm{p}-\mathrm{j}}=.697, \beta_{\mathrm{CG}}=-$. 407, $\mathrm{P}<.05$ ). Model 3 shows the results of the regression analysis involving the control variables, entering independent variable P-O fit, P-J fit in Model 4 had a significant effect on turnover intention $\left(R_{p-0}^{2}=.457, F=75\right.$. 652; $\mathrm{R}_{\mathrm{p}-\mathrm{j}}^{2}=$. 492, $\left.\mathrm{F}=57.690, \mathrm{P}<.05\right)$. Results of Model 5 shows that adding career growth significantly to the model $\left(\Delta \mathrm{R}_{\mathrm{p}-\mathrm{o}}^{2}=.043 ; \Delta \mathrm{R}_{\mathrm{p}-\mathrm{j}}^{2}=.059, \mathrm{P}<.05\right)$ and enhanced the explanatory power of the model. The absolute value of the coefficients of the independent variables in Model 5 is less than it in Model $4(.608<.824 ; .697<.914, \mathrm{P}<.05)$, suggesting that the career growth plays a partial mediating role between $\mathrm{P}-\mathrm{O}$ fit and turnover intention, as well as P-J fit and turnover intention. Hypothesis 3 was founded.

Table 3 Results of regression analysis $(\mathrm{N}=183)$

\begin{tabular}{|c|c|c|c|c|c|c|c|c|c|c|}
\hline \multirow{2}{*}{ Variable } & \multicolumn{4}{|c|}{ Career growth } & \multicolumn{6}{|c|}{ turnover intention } \\
\hline & Mod & el 1 & Mo & el 2 & Mo & el 3 & Mo & el 4 & Mo & el 5 \\
\hline Age & & .127 & & -.040 & & -.086 & & .201 & & .185 \\
\hline Working life & -.088 & -.163 & -.115 & -.111 & 002 & .052 & 041 & -.036 & -.002 & -.081 \\
\hline P-O fit & & & $.579 *$ & & & & $\begin{array}{c}- \\
824^{*}\end{array}$ & & $\begin{array}{c}-. \\
608^{*}\end{array}$ & \\
\hline P-J fit & & & & $.533 *$ & & & & $\begin{array}{c}-. \\
914^{*}\end{array}$ & & $-.697 *$ \\
\hline $\begin{array}{l}\text { Career } \\
\text { Growth }\end{array}$ & & & & & & & & & $\begin{array}{c}- \\
374^{*}\end{array}$ & $-.407^{*}$ \\
\hline $\mathbf{R}^{2}$ & $021^{*}$ & $.030^{*}$ & $434 *$ & $336^{*}$ & $.000 *$ & $002 *$ & $457^{*}$ & $492 *$ & $.500 *$ & $551^{*}$ \\
\hline Adjusted $\mathbf{R}^{2}$ & $.016^{*}$ & $.020^{*}$ & $428 *$ & $.324^{*}$ & $\begin{array}{c}-. \\
006 *\end{array}$ & $\begin{array}{c}-. \\
009 *\end{array}$ & $451^{*}$ & $483 *$ & $.491 *$ & $541^{*}$ \\
\hline $\begin{array}{c}\mathbf{F} \\
\Delta \mathbf{R}^{2}\end{array}$ & $\begin{array}{c}3 . \\
933^{*}\end{array}$ & $\begin{array}{c}2 . \\
821^{*}\end{array}$ & $\begin{array}{c}69 . \\
138 * \\
.413^{*}\end{array}$ & $\begin{array}{c}30 . \\
129 * \\
.306 *\end{array}$ & $.001^{*}$ & . 203* & $\begin{array}{c}75 . \\
652^{*} \\
.457^{*}\end{array}$ & $\begin{array}{c}57 . \\
690^{*} \\
.490^{*}\end{array}$ & $\begin{array}{c}59 . \\
608^{*} \\
.043^{*}\end{array}$ & $\begin{array}{c}54 . \\
716^{*} \\
059^{*}\end{array}$ \\
\hline
\end{tabular}

Notes*. $\mathrm{P}<.05$.

\section{Results and Discussion}

Turnover intention is mainly affected by three factors, including individual factors, environmental factors and structural factors (Xia, 2007). Each person is affected by various factors, so these factors are independent or interactive to the employees' turnover intention. The mechanism is mainly based on whether their own conditions and characters fit with the organization or job. When there is a good matching degree, employee's work will be very smooth and their mood will always be cheerful. So it is unlikely to have turnover intention but not vice versa. Therefore, the turnover intention decreases with the increase of P-O fit, P-J fit degree, that is to say, a higher degree of fitting will lead to lower turnover intention.

P-O fit and P-J fit can have an effect on turnover intention through career growth. Foreign researchers have shown that the majority of knowledge workers pay more attention to career motivation rather than material motivation (Tampoe, 1993). An analysis of the factors of job hunting for graduates in our country also showed that $83.3 \%$ of people regard career development as the primary consideration[7](Hu \&Weng, 2008), so career growth has become the main goal that people pursue in their workvi. P-O fit and P-J fit help speed up career growth and promote employees' 
occupation career development. The existing research has proved that career growth and turnover intention are negatively correlated, so if the fit is poor, the staff can not get a better career growth, employees are likely to have turnover intention. Of course, P-O fit, P-J fit can also be directly related to the intention to leave, so the career growth in fitting and turnover intention is a part of the intermediary role.

\section{References}

[1] Han Yi. The mediating role of personal organization fit, perceived organizational support and turnover intention [J], Economic Management, 2009, 458(02):84-91.

[2] I. S. Oh, R. P. Guay, K. Kim, C. M. Harold, J. H. Lee, et al. Fit happens globally: A meta-analytic comparison of the relationship of person-environment fit dimensions with work attitudes and performance across East Asia, Europe and North America[J], Personnel Psychology, 2014, 67(01):99-152.

[3] A. L. Kristof, Person-organization fit: An integrative review of its conceptualizations, measurement, and implications[J]. Personnel Psychology, 1996, 49(01):1-49.

[4] Weng Qingxiong, Xi Youmin. Career growth and turnover intention: the moderating role of career commitment and perceived opportunity [J], Nankai Business Review, 2010, 13(02):119-131.

[5] W. H. Mobley, , R. W. Griffeth, H. H. Hand, B. M. Meglino. Review and conceptual analysis of the employee turnover process[J], Psychological Bulletin, 1979, 86(03): 493-522.

[6] Wen Zhonglin, Zhang Lei, Hou Jietai, Liu Hongyun. The test procedure and its application of mediating effect[J], Journal of Psychology, 2004, 36(5):614-620.

[7] Hu Bei, Weng Qingxiong. The empirical study of organizational attractiveness: Based on the angle of prospective employees[J]. Forecasting, 2008, 27(01):53-59. 